\title{
CROHN'S DISEASE WITH CARCINOMA OF THE COLON
}

\author{
A. Davis, M.B., M.R.C.P.(Edin.) \\ Late Medical Registrar, Royal Infirmary, Sheffield* \\ J. P. Caley, M.B., M.R.C.P. \\ Senior Medical Registrar, Royal Infirmary, Sheffield
}

Crohn's disease is not usually regarded as a premalignant state. Recent reviews of the literature ${ }^{1,2}$ make scant reference to an association of regional enteritis with carcinoma. However, at the World Congress of Gastro-enterology, 1958, Crohn observed that he had seen two cases of carcinoma of the small intestine co-existing with regional enteritis. ${ }^{3}$

Rare cases of carcinoma arising in patients with pre-existing Crohn's disease have been described in both the small and large intestine. Van Patter mentions a case of malignant change occurring in association with regional enteritis of the colon, whilst Warren and Sommers ${ }^{8}$ reported an adenocarcinoma developing in an area of Crohn's disease in the ascending colon. In addition, Ginzburg ${ }^{5}$ and Kornfeld ${ }^{6}$ each describe a case of carcinoma arising in the jejunum in areas affected by regional enteritis. In view of this uncommon association the following case is reported.

\section{Case Report}

M.E.S., a housewife, aged 44 years, was referred to the surgical out-patient department in April 1956, with a three months' history of attacks of colicky lower abdominal pain. The pain commenced in the epigastrium and radiated diffusely over the lower abdomen, tending to be worse after food, and being eased occasionally by alkalis. Nausea was present in the attack, but there was no vomiting. Bowel movements were regular, except during an attack, when constipation was noted. Examination revealed central epigastric tenderness, but no other significant abnormality. Rectal examination was negative. A barium meal, cholecystogram, and catheter specimen of urine were normal. Observation was undertaken in the out-patient clinic, and in July 1956 a further barium meal was again reported as normal. Follow-through was not performed. In August

\footnotetext{
* Present address; Medical Research Laboratory, P.O. Box 30141 , Nairobi, Kenya.
}

r 956 the attacks of abdominal pain became increasingly severe, and were associated with vomiting of undigested food. It was therefore decided to advise laparotomy.

At operation (Mr. P. D. Livingstone) the caecum and appendix were reddened and oedematous. The serosa of the terminal three feet of ileum showed increased vascularity, and the mesentery was thickened and contained large, flesh-coloured glands. No abnormality was detected in any other viscera. An operative diagnosis of Crohn's disease was made, and a mesenteric gland removed for section. The post-operative course was uneventful. The operative diagnosis was substantiated by the histological appearances which showed giant cell-epithelioid cell systems without central caseation present near the periphery gland. The appearances were entirely consistent with Crohn's disease (Fig. I).

Following discharge on a low residue diet, the patient remained well for the next six months, apart from occasional attacks of mild lower abdominal discomfort, and in April 1957 a barium enema showed narrowing of the caecum with proximal small bowel dilatation. Fifteen months later, in July $195^{8}$, her symptoms altered. Attacks of diffuse lower abdominal pain occurred together with diarrhoea, and the passage of four to six loose stools per day containing blood and mucus. There was associated anorexia and weight loss. Over the course of the next two months her symptoms became increasingly severe, and in October 1958 she was admitted to the Royal Infirmary, Sheffield.

Examination revealed a thin, apprehensive, afebrile woman. The abdomen was slightly distended in the lower half, and there was marked tenderness in the left iliac fossa. There was no hepatosplenomegaly, nor were the kidneys palpable. Peristalsis was not seen. No free fluid was detected. A healed right paramedian scar and a sebaceous cyst in the epigastrium were 


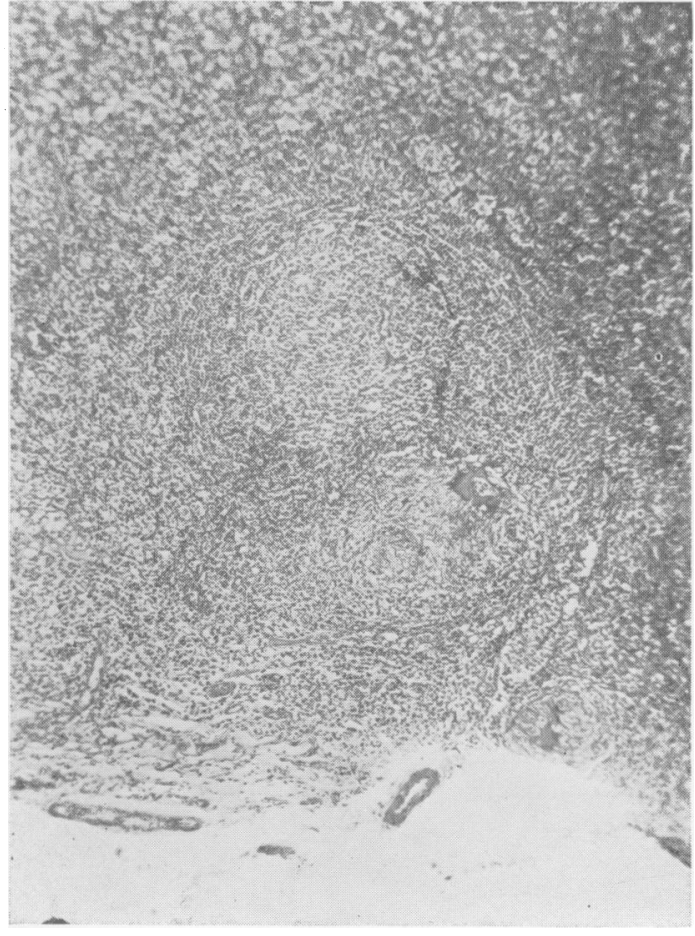

FIG. I

noted. The rectum was empty. Sigmoidoscopy to I I $\mathrm{cm}$. was normal, but at that level a black, lustreless stool was seen, with specks of blood on its surface. There were no other significant abnormalities on physical examination. Blood pressure $140 / 85 \mathrm{~mm}$. Hg.

\section{Investigations}

W.R. negative. E.S.R. (Wintrobe) $31 \mathrm{~mm}$. in one hour. Hb. Io g./100 $\mathrm{ml} .(7 \mathrm{r} \%)$ W.B.C. 6,000 .

Stool: Benzidine reaction for occult blood strongly positive. No ova or parasites seen. Culture for $M$. tuberculosis negative.

Catheter specimen of urine showed no abnormality.

Blood urea $21 \mathrm{mg}$./ $100 \mathrm{ml}$, serum sodium I4I mEq./l., chloride $100 \mathrm{mEq} . / \mathrm{l}$,, potassium $3.7 \mathrm{mEq} .11$.

Serum proteins $7.7 \mathrm{~g} . / 100 \mathrm{ml}$. Electrophoresis showed a normal pattern.

A five-day fat balance study on a $5^{0}-\mathrm{g}$. daily fat intake showed an average daily output of 2.5 g. of fat.

Chest X-ray was normal.

A barium meal and follow-through showed narrowing of the terminal ileum and caecum (Fig. 2).

Barium enema disclosed an almost complete

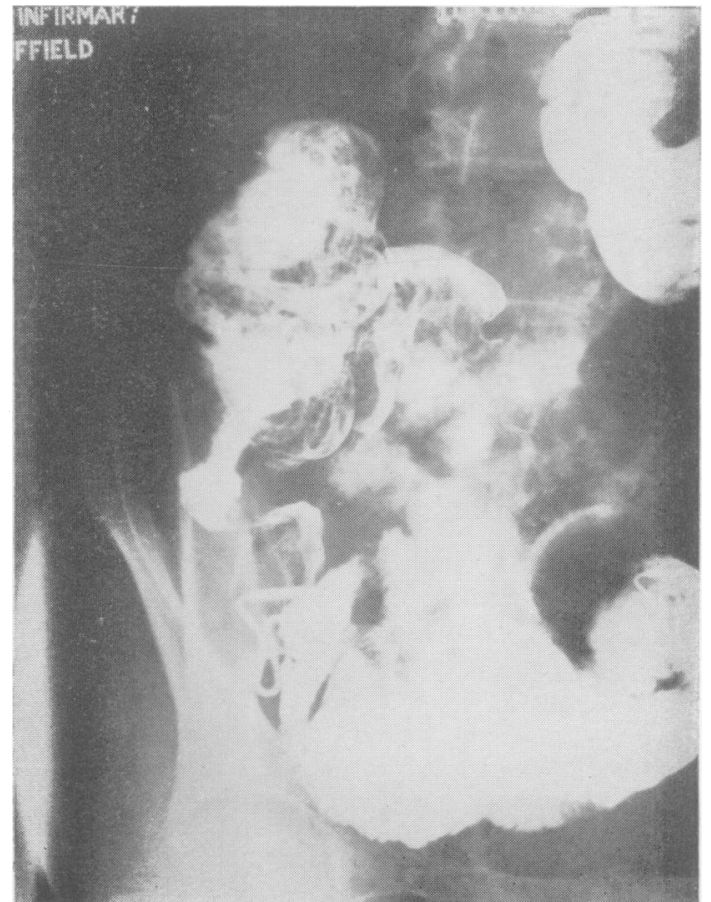

FIG. 2

hold up of barium by an irregular area of narrowing in the sigmoid colon (Fig. 3). The radiological appearances were suggestive of carcinoma, but Crohn's disease of the colon could not be excluded with certainty. In view of the radiological findings it was decided that a further laparotomy was indicated.

\section{Operative Findings}

Following preparation for surgery, exploration was undertaken on November 4, 1958, by $\mathrm{Mr}$. J. E. Oliver, through a left paramedian incision. A carcinoma of the pelvi-rectal junction was found, and conservative resection with an end-toend anastomosis performed. There were no metastases present. In addition, the caecum and terminal ileum were found to be thickened and densely bound down by matted adhesions presenting a picture of quiescent Crohn's disease.

The pathological specimen comprised $28 \mathrm{~cm}$. of colon, containing a large ulcerating growth, $8 \mathrm{~cm}$. by $4 \mathrm{~cm}$., which had invaded through the bowel wall into the adjacent fat. Histology showed a well-differentiated adenocarcinoma invading all coats of the intestine (Fig. 4). There was a secondary deposit in the peri-colic fat. The patient made a good recovery from operation, and when last seen in February I959 had 


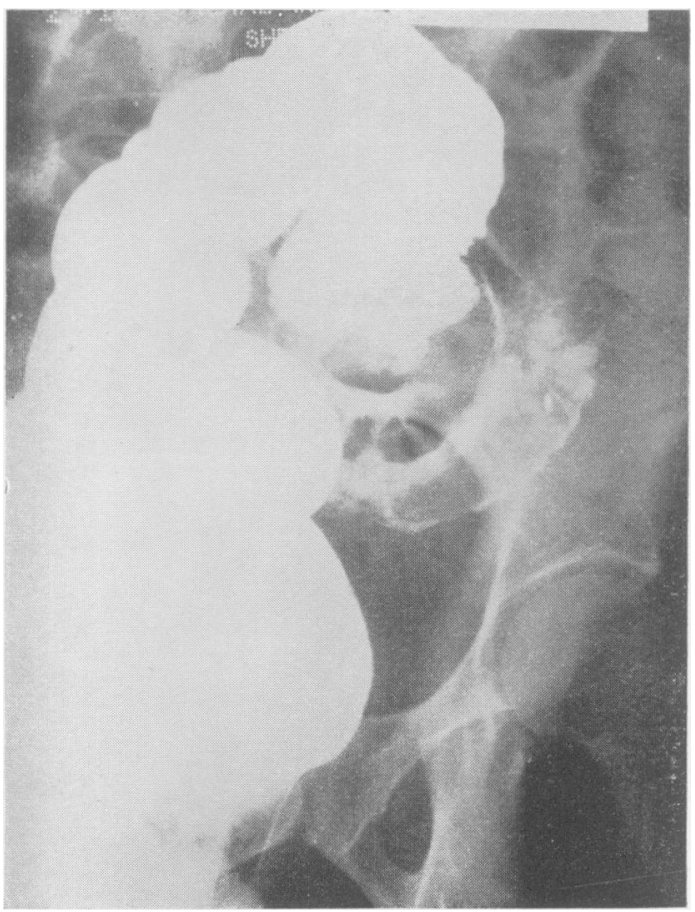

FIG. 3

gained over one stone in weight and was symptom free.

\section{Discussion}

Although Crohn's disease may occur at any age, it commonly arises in the young. ${ }^{3}$ Conversely, the incidence of carcinoma of the colon rises with advancing years, becoming maximal in the age groups 50 to 70 years. ${ }^{2}$ The natural history of Crohn's disease extends over many years, and the majority of patients with this condition will live to an age overlapping those age groups in which colonic carcinoma reaches its peak incidence. In view of this, one would expect occasional association of the two conditions, but in fact the co-existence of small intestinal Crohn's disease and carcinoma of the colon is distinctly unusual.

The rare development of small intestinal carcinoma on an area of regional ileitis or jejunitis could conceivably be related to the presence of a pre-existing chronic inflammatory lesion, in parallel with the occurrence of cancer arising on sites of chronic irritation elsewhere in the body. Similarly, carcinoma of the colon arising on an area of regional colitis is most uncommon, although the same argument is applicable.

It is interesting to note that in a recent exhaustive study of Crohn's disease, Van Patter ${ }^{7}$

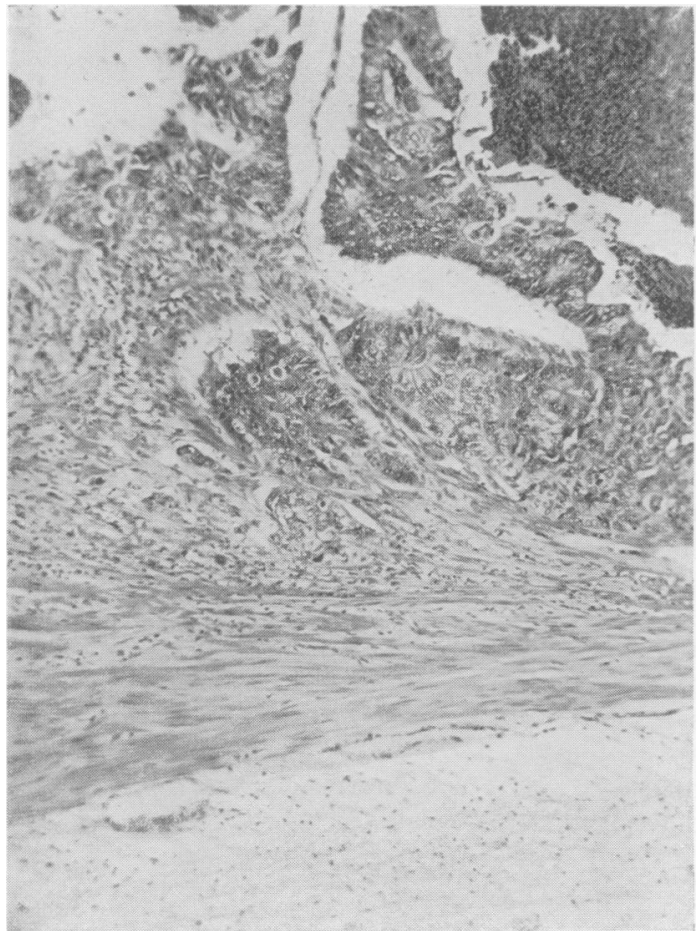

FIG. 4

observed an oedematous, hyperaemic mucosa in the rectum and sigmoid in a small number of cases of Crohn's disease with no demonstrable colonic involvement. It was considered that these lesions were of no particular significance. However, in two of the cases the mucosa showed a polypoid appearance. In addition, mucosal ulcerations in the rectum and sigmoid were seen in 56 of 600 cases, and when these cases were observed over the course of many years they showed a general trend to stricture formation at the site of these ulcers. Of these 56 cases, approximately one-third showed radiological evidence of purely small intestinal or proximal colonic Crohn's disease. Thus it may be accepted that, in a very small number of patients with small intestinal or proximal colonic Crohn's disease, non-specific mucosal changes occur in the rectum and sigmoid, in the absence of demonstrable direct colonic involvement. Furthermore, these changes consist of hyperaemia, oedema, or rarely a polypoid appearance, and may over the course of years lead to a stricture in the distal colon. It is interesting to speculate whether carcinomatous metaplasia of the cells of these areas of rectal and sigmoid mucosa could occur over the years, and if this mechanism could provide an explanation of the occurrence of malignancy in the present case. If this is so, it is surprising that the association 
of Crohn's disease and cancer of the colon is a rare one, and it would seem probable that the association of these two conditions in this patient is fortuitous.

Recurrent abdominal symptoms in Crohn's disease are not uncommon--exacerbation of the original disorder, subacute or acute intestinal obstruction, fistulae formation, extension of the disease in the small gut, or extension to the large bowel usually provide the explanation. Rarely, however, malignant change may occur, and for these reasons a full investigation of all recurrent symptoms in Crohn's disease is essential. In this context both barium meal with follow-through and barium enema must be performed to reach an accurate diagnosis, and the importance of the latter in the diagnosis of recurrence was stressed by Garlock and Crohn. ${ }^{4}$ Biopsy of any abnormal areas in the rectum and sigmoid should be undertaken and the attribution of recurrent abdominal symptoms in a patient with Crohn's disease to an exacerbation of this disorder should only be made with a full realization of the other various diagnostic possibilities.

\section{Summary}

A case of carcinoma of the distal colon arising in a patient with small intestinal and proximal colonic Crohn's disease is described. No evidence of distal colonic Crohn's disease was found. The difficulties of diagnosis are noted.

\section{Acknowledgments}

We thank Dr. H. P. Brody and Mr. Clifford Jones for permission to publish this case, Professor A. W. Kay for helpful criticism, and Dr. O. G. Dodge for the histological reports.

\section{REFERENCES}

I. ARMITAGE, (i., and WILSON, M. (1950), Brit. F. Surg., $38,182$.

2. BOCKUS, H. L. (I 944), ' Gastro-enterology,' vol. i I, p. 755 W. B. Saunders \& Co.

3. CROHN, B. B., and YARNIS, H. (1958), 'Regional Ileitis,' and ed. New York: Grune and Stratton.

4. GARLOCK, J. H., and CROHN, B. B. (1945), f. Amer. med. Ass., 127, 205

5. GIN7.BURG, L., SCHNEIDER, K. M., DREIZIN, D. H. and LEVINSON, C. (1956), Surgery, 39, 347.

6. KORNFELD, P., GINZBURG, L., and ALDERSBERG, D. (1957), Amer. F. Med., 23, 493 .

7. VAN PATTER, W. N., BARGEN, J. A., DOCKERTY, M. B., FELDMAN, W. H., MAYO, C. W., and WAUGH, J. M. (1954), Gastroenterology, 26, 347.

8. WARREN, S., and SOMMERS, S. C. (1948), Amer. F. Path., 24, 475 .

9. World Congress of Gastro-enterology (1958), vol. I1, p. 1342 Baltimore: The Williams \& Wilkins Co.

\section{DIETARY FAT, CHOLESTEROL METABOLISM \& CORONARY DISEASE}

(Postgraduate Medical fournal, April I 959)

Price 6s. 6d. post free THE EPIDEMIOLOGY OF ISCHAEMIC
HEART DISEASE

B. Bronte-Stewart, M.D., M.R.C.P.

THE REGULATION OF THE HUMAN SERUM-CHOLESTEROL LEVEL

H. Gordon, M.D. (Cape Town)

THE RELATIONSHIP BETWEEN THE SERUM LIPIDS AND THE DEVELOPMENT OF ISCHAEMIC HEART DISEASE B. Bronte-Stewart, M.D., M.R.C.P.

THE COAGULABILITY OF BLOOD IN RELATION TO CORONARY HEART DISEASE

C. Merskey, M.D. (Cape), M.R.C.P. (London), and H. Lackner, M.D. (Leeds), M.R.C.P. (London)
THE METABOLISM OF CHOLESTEROL

B. Lewis, Ph.D., M.D. (Cape Town)

PRESENT CLINICAL APPLICATIONS OF DIET TO THE PREVENTION OF ISCHAEMIC HEART DISEASE

J. F. Brock, D.M., F.R.C.P.

MYOCARDIAL INFARCTION-THE COMPARATIVE RACIAL PREVALENCE IN CAPE TOWN, 1957-AN ELECTROCARDIOGRAPHIC STUDY

V. Schrire, M.Sc., Ph.D., M.B., Ch.B. (Cape Town), M.R.C.P. (London and Edinburgh)

ISCHAEMIC HEART DISEASE IN AFRICAN POPULATIONS

J. F. Brock, D.M., F.R.C.P., and H. Gordon, M.D. (Cape Town)

Published by

THE FELLOWSHIP OF POSTGRADUATE MEDICINE

60, Portland Place, London, W.1 